\title{
Developing Strategies for Early Detection of Hepatitis B Infection
} Saurabh Bandhavkar*

Department of Biochemistry, G. S. Medical College and KEM Hospital, Mumbai, Maharashtra, India

"Corresponding author: Saurabh Bandhavkar, Department of Biochemistry, G. S. Medical College and KEM Hospital, Mumbai, Maharashtra, India, Tel: +91-8879879008; E-mail: mukulrocks93@gmail.com

Received date: January 20, 2016; Accepted date: February 12, 2016; Published date: February 19, 2016

Copyright: (C) 2016 Bandhavkar S. This is an open-access article distributed under the terms of the Creative Commons Attribution License, which permits unrestricted use, distribution, and reproduction in any medium, provided the original author and source are credited.

\begin{abstract}
Hepatitis B caused by hepatitis B virus (HBV) is regarded as the most common form of chronic hepatitis worldwide. Around $15 \%-40 \%$ of people infected with HBV develop HBV-related complications and approximately $25 \%$ die as a result of these complications. Since HBV is infectious and spreads through blood, semen and other body fluids, it will be easy to detect the presence of this virus in these body fluids. Polymerase chain reactions (PCR) assays are often employed to detect these viruses in blood. While most of these assays generally rely on detection of HBV Surface Antigen (HBsAg) or hepatitis b core IgM Antibody (anti-HBc IgM), recent developments have made possible the detection of HBV DNA in blood. These assays, however, necessitate the requirement of adequate controls to distinguish true from false negative results. To address this issue, we have developed positive controls for Hepatitis B virus using molecular biology techniques. These controls can be used in PCR assays for detection of HBV by competitive amplification, thereby allowing detection of false negatives. The controls developed in this study were successfully tested with virus-seeded blood sample concentrates.
\end{abstract}

\section{Keywords: HBV; pBS; Controls}

\section{Introduction}

Hepatitis B is a devastating infectious disease affecting the liver that is caused by the hepatitis B virus (HBV). It is capable of causing both acute and chronic infections. No symptoms can be detected in many cases during the initial infection. These symptoms spontaneously develop which can be seen as vomiting, yellow fever, abdominal pain and dark urine. Mode of transmission is generally through blood and other body fluids [1]. Contact with infected fluids during childhood or infection during birth is the most common cause that results in chronic hepatitis B. Intravenous drug use and sexual intercourse may also lead to transmission of the virus. About a third of the population is infected by hepatitis B virus at some point in their life [2]. Over $8,00,000$ patients die due to hepatitis B each year, majorly due to liver diseases [3]. Therefore, early detection and routine surveillance of virus are the routes to management, control and eradication of this disease. Many molecular-biology techniques are available for detection of virus, PCR being the most widely adopted. However, one problem associated with any molecular detection assay is the potential for false negative results. A false negative result may appear due to many cases such as PCR inhibitors, poor DNA extraction, and target DNA degradation before amplification or even manual errors in setting up a reaction [4-15]. Therefore, the presence of positive control will ensure the efficient run of the PCR as well as help in monitoring the PCR procedure $[16,17]$. Ultimately the positive control can be monitored by resolving the reaction products on an agarose gel [12]. In this study, we have developed positive controls by amplifying the surface antigen gene present in the HBV genome. The positive control used is a $208 \mathrm{bp}$ long DNA. Compared to nested PCR as the reference standard, the real-time assay has a sensitivity of $99.5 \%$, specificity of $100 \%$, positive predictive value of $100 \%$, and negative predictive value of $99.6 \%$ for the detection of viruses. Our assay uses species-specific forward primers in combination with a conserved reverse primer and largely overcomes primer competition for the minor species DNA. With a blind panel of clinical samples, we successfully identified the species in 12/16 mixed infections. This assay was further validated with 97 blood samples and demonstrated a specificity and sensitivity for single infections of $100 \%$ compared with nested PCR as the "gold standard.

\section{Materials and Methods}

\section{HBV viruses and viral DNA extraction}

Blood infused with HBV virus was collected in an EDTA vacutainer. The tube was centrifuged at $25000 \mathrm{rpm}$ to separate RBCs and the separated plasma was transferred in a separate eppendorf and stored at $-80^{\circ} \mathrm{C}$. Viral DNA was extracted by taking $200 \mu \mathrm{l}$ of the plasma with the help of Invitrogen's viral DNA kit by Life Technologies using the manufacturer's instructions. The viral DNA was eluted in $40 \mu \mathrm{l}$ of elution buffer. For long term use, extracted DNA was preserved at $-80^{\circ} \mathrm{C}$ whereas for short term use, it was preserved at $-20^{\circ} \mathrm{C}$.

\section{Preparation of positive controls of viral DNA}

The positive control DNA template was constructed using two oligonucleotide primers which were custom made. Each primer consisted of a positive strand and a complementary negative strand, so that it can be easily annealed in a DNA fragment [5]. The first pair consisted of Forward (+), AAAATTCGCAGTCCCCAAC and the forward (-), TTTTAAGCGCAGGGGTTG. The second pair consisted of Reverse (+) and the reverse (-), with sequences GTCCCGTGCTGGTAGTTGAT and CAGGGCACGACACCATCAACTA respectively (Figure 1). The primers were designed to have binding sites for $\mathrm{HBV}$ S-gene forward(S-gene+151 AAAATTCGCAGTCCCCAAC) and the S-gene reverse (S-gene -323 ATCAACTACCAGCACGGGAC) in the S-gene forward (+) and the S-gene reverse (-) respectively. The complementary primers were denatured at $95^{\circ} \mathrm{C}$ and reannealed at 
$58^{\circ} \mathrm{C}$. The primers were fashioned in such a manner that they could be used in a blunt end ligation using a single restriction site.

\section{tggccaaaattcgcagtccccaacctccaatcactcaccaacctcttgtcctccaacttg tcctggctatcgctggatgtgtctgcggcgtttatcatattcctcttcatcctgctgctatgc ctcatcttcttgttggttcttctggactaccaaggtatgttgcccgtttgtcctctacttccaggaa catcaactaccagcacgggaccatgcagaacctgcacgattcctgctca}

Figure 1: Nucleotide sequence of S-gene. The former boldface represents the forward primer (+) and latter represents the reverse primer (-).

\section{Preperation of S-gene amplicon}

An amplicon of HBV S-gene with a size of 208 bp was generated from the viral DNA using the above primers by setting up a RT-PCR with the help of Qiagen's one step PCR kit. The Qiagen's one step PCR kit was used with a $30 \mu \mathrm{l}$ reaction mixture along with $1.2 \mu \mathrm{l}$ of enzyme mixture supplied by the kit (along with hot start Pfu. Pol), Pfu buffer, $10 \mathrm{pmol}$ of each (S-gene forward and S-gene Reverse) primers $(0.5 \mu \mathrm{l})$, $400 \mathrm{Um}$ (each) of deoxynucleoside triphosphate and $5 \mathrm{mM} \mathrm{MgCl}_{2}$. The thermo cycling conditions for PCR included heat start activation of Pfu Polymerase at $94^{\circ} \mathrm{C}$ for 5 mins followed by 40 cycles of PCR amplification with each cycle consisting of $30 \mathrm{~s}$ of denaturation at $94^{\circ} \mathrm{C}, 30 \mathrm{~s}$ of annealing at $60^{\circ} \mathrm{C}, 45$ cycles of elongation at $72^{\circ} \mathrm{C}$ and one final cycle of elongation at $72^{\circ} \mathrm{C}$ for 10 mins [6]. The PCR was carried out using GeneAmp PCR system 2700 from applied bio-systems. The probes used for monitoring the RT-PCR were Vic and Fam. The amplicon was loaded in a $0.75 \%$ agarose gel and checked for its purity and size (208 bp) along with a $100 \mathrm{bp}$ thermo fisher DNA ladder. The gel was cut at the appropriate band size and the amplicon was gel eluted in $35 \mu \mathrm{l}$ of TE buffer provided in the Qiagen's gel extraction kit and was stored at $-20^{\circ} \mathrm{C}$ for short term use and $-80^{\circ} \mathrm{C}$ for long term use.

\section{Manipulation of viral DNA and vector DNA}

Restriction digestion of the vector DNA and agarose gel electrophoresis of DNA were carried out using standard protocols. The vector used was pBlueScript (pBS) KS II+ and the restriction site targeted in the Multiple cloning site of the pBS vector was Eco RV (GAT^ATC). The enzyme was found to cut the site in 15 mins and the reaction was set up accordingly $[7,8]$. The ligation and cloning of DNA was carried out using T4 DNA ligase from Promega (Madison, WI) according to manufacturer's instructions. Being a blunt end ligation, higher quantities of ligase and insert (amplicon) were added to the reaction mixture, along with Polyethylene glycol (PEG) so as to aid the blunt end ligation. Ligation was set up at lower temperatures than usual $\left(22^{\circ} \mathrm{C}\right)$ so as to avoid heat inactivation of PEG [9].

\section{Transformation and screening for positive colonies}

The ligation mixture was added to $100 \mu \mathrm{l}$ of competent Top $10 \mathrm{E}$. coli cells and transformation was carried out using standard protocols. $10 \mu \mathrm{l}$ of transformation was then loaded on luria agar plate containing $1 \mathrm{mg} / \mathrm{ml}$ of Ampicillin, $100 \mathrm{mM} / \mathrm{ml}$ of Isopropyl beta-Dthiogalactopyranoside (IPTG) and $40 \mu \mathrm{g} / \mathrm{ml}$ of X-gal (5-bromo-4chloro-3-indolyl-beta-D-galactopyranoside). The plates were incubated overnight at $37^{\circ} \mathrm{C}$ and based on blue-white screening principle [10] (Figure 2), white colonies were picked and screened for presence of HBV amplicon by setting up a screening PCR. The positive clones obtained were reconfirmed using two pairs of vector specific primers, which were so designed that they amplify the entire cloned region of S-gene of $\mathrm{HBV}$ along with some portion of the $\mathrm{pBS}$ vector.
The first pair consisted of T17 forward (+), TAATACGACTCACTATAGGG and T17 forward (-) ATTATGCTGAGTGTGATATCCC. The second pair consisted of M13 reverse (+), GGAAACAGCTATGACCATGA and M13 reverse (-), CCTTTGTCGATACTGGTACT. The primers were designed to have binding sites for sequence TAATACGACTCACTATAGGG and reverse sequence TCATGGTCATAGCTGTTTCC in the T17 forward (+) and M13 reverse (-) primers, respectively, described above. The amplicon obtained using these primers in a wild type pBS vecor was $201 \mathrm{bp}$, whereas in a recombinant $\mathrm{pBS}$ vector containing the cloned HBV region, the amplicon generated using these primers was found to be $409 \mathrm{bp}$ long (Figure 3). This indicated the successful insertion of portion of S-gene of HBV in the $\mathrm{pBS}$ vector.

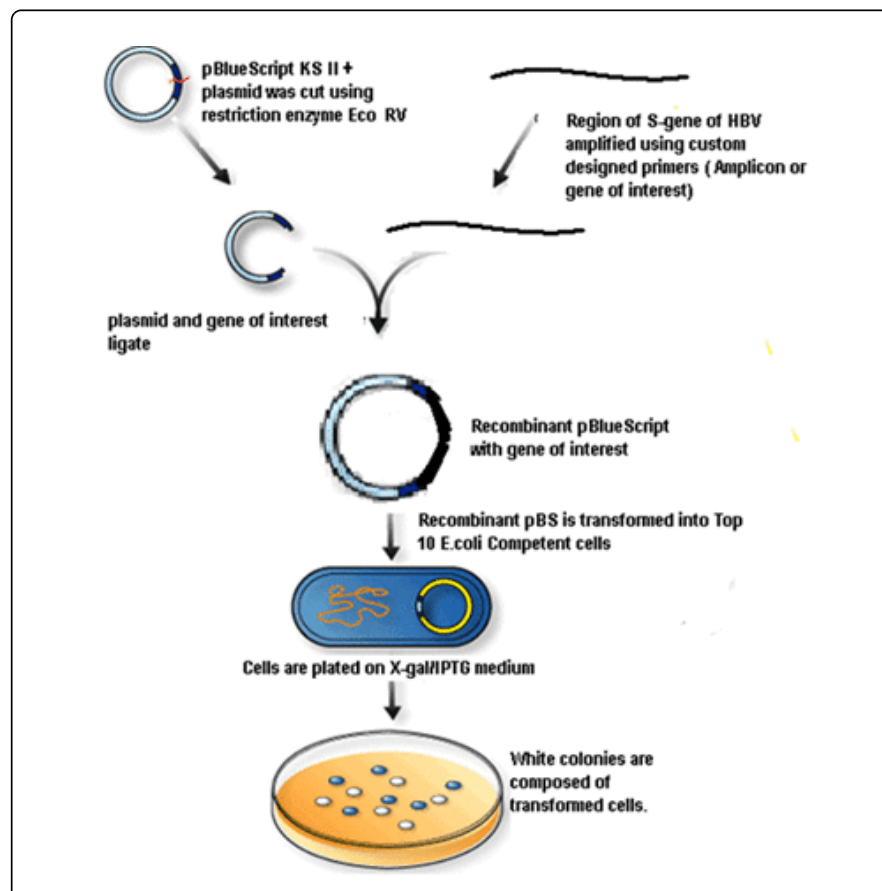

Figure 2: Cloning of Portions of S-gene into pBlueScript KS II +vector and transformation into top $10 \mathrm{E}$. coli competent cells.

Thus, the PCR product(amplicon) obtained after amplification by the custom designed primers was cloned in the multiple cloning site (MCS) of pBlueScript (pBS) KS II+vector using Eco RV restriction site to generate the recombinant plasmid containing the S-gene of HBV. The nucleotide sequence derived from the cloned template in $\mathrm{pBS}$ matched to the sequences of the oligonucleotide primers used to 
construct the positive control template and was found to be $208 \mathrm{bp}$ long, as expected. The purity of the template DNA was tested on agarose gel electrophoresis. The purified DNA template was then stored in RNAse free Tris-EDTA buffer $(\mathrm{pH} 8.0)$ at $-80^{\circ} \mathrm{C}$. The template DNA used was serially diluted and used in the assay so as to determine the Minimum detection level (MDL).

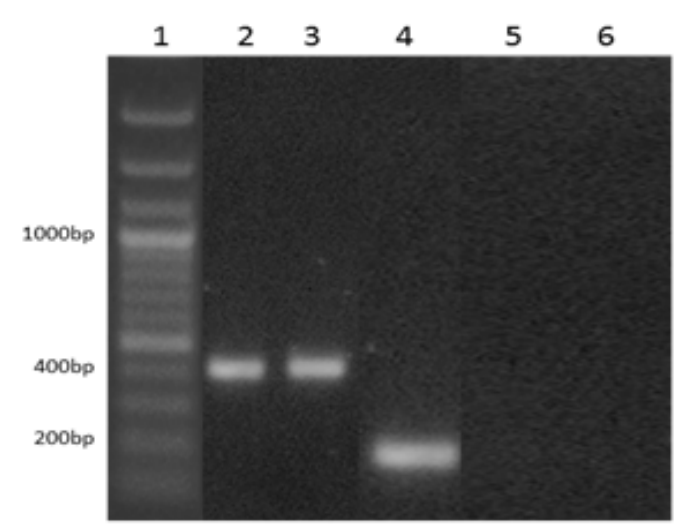

Figure 3: Screening PCR using white colonies and vector specific primers (M13 rev. and t17 fwd.). Lane 1: 100 bp ladder; Lane 2, 3: Recombinant pBS; Lane 4: Wild type pBS; Lane 5: Negative control; Lane 6: Distilled water.

\section{Results}

The construction of positive control for Hepatitis B virus was described in materials and methods. The MDL of the positive control was determined to be $0.12 \mathrm{pg}$ for RT-PCR. The stability of the controls was tested under changes in storage conditions. The positive controls were stable for at least six months when stored in Tris-EDTA buffer at $-80^{\circ} \mathrm{C}$. In the same period, the control was slightly destabilized when stored at $-20^{\circ} \mathrm{C}$ and slightly more destabilized when stored at $4^{\circ} \mathrm{C}-10^{\circ} \mathrm{C}$.

Inhibition studies: One of the major problems associated with PCR diagnosis is the presence of PCR inhibitors [6]. The presence of PCR inhibitors was evaluated in blood, serum and plasma. The results showed no inhibition of amplification of viral DNA extract.

\section{Discussion}

An extremely important step towards the management control and eradication of Hepatitis B virus in course of Hepatitis B disease is its early detection. PCR is widely used molecular assay for detection of the infection at an early stage [11]. Although PCR is sensitive and specific for is target, there are still concerns with false negative results. In this research, we therefore developed positive controls which can help identify and detect false negative result and thus increase the specificity and sensitivity of the PCR assays [13]. A major advantage associated with the use of these positive controls is that they detect the HBV DNA. The HBV DNA is a reliable marker for detection of hepatitis B
Virus [14] which can help in (1) distinguishing active infection from inactive (2) help in monitoring the patient's response to anti-HBV therapy (3) Further, HBV DNA can be detected in blood almost 21 days prior to the appearance of HBsAg in blood, thus facilitating early detection [15]. Thus, developing positive controls is a very economical and time saving method for easy detection of hepatitis B virus.

\section{Acknowledgement}

I would sincerely like to thank the entire team of BioGenomics Ltd for their support and provision of all the required materials.

\section{References}

1. Schlicht HJ, Schaller H (1989) The secretory core protein of human hepatitis B virus is expressed on the cell surface. J Virol 63: 5399-5404.

2. Mahoney FJ (1999) Update on diagnosis, management, and prevention of hepatitis B virus infection. Clin Microbiol Rev 12: 351-366.

3. Chen HL, Chang MH, Ni YH, Hsu HY, Lee PI, et al. (1996) Seroepidemiology of hepatitis B virus infection in children: Ten years of mass vaccination in Taiwan. JAMA 276: 906-908.

4. Das A, Spackman E, Senne D, Pedersen J, Suarez DL Suarez (2006) Development of an Internal Positive Control for Rapid Diagnosis of Avian Influenza Virus Infections by Real-Time Reverse TranscriptionPCR with Lyophilized Reagents. J Clin Microbiol 4: 3065-3073.

5. Yang X, Scheffler BE, Weston LA (2006) Recent developments in primer design for DNA polymorphism and mRNA profiling in higher plants. Plant Methods 2: 4.

6. Thomas W, Hugh G, Annette G (2003) PCR technologies-Current innovations. (2nd edn.) CRC press, USA.

7. Wilson CM, Serrano AE, Wasley A, Bogenschutz MP, Shankar AH, et al. (1989) Amplification of a gene related to mammalian mdr genes in drugresistant Plasmodium falciparum. Science 244: 1184-1186.

8. Klein RD, Selsing E, WellsRD (1980) A rapid microscale technique for isolation of recombinant plasmid DNA suitable for restriction enzyme analysis. Plasmid 3: 88-91.

9. Ma J, Wang YG, Wang YJ (2013) A simple, fast and efficient method for cloning blunt DNA fragments. African Journal of Biotechnology 12: 4094-4097.

10. Maas S (1999) Efficient and rapid procedure for blue-white screening of recombinant bacterial clones. Biotechniques 27: 1126-1128.

11. Hoofnagle JH, Di Bisceglie AM (1991) Serologic diagnosis of acute and chronic viral hepatitis. Semin Liver Dis 11: 73-83.

12. Farcas GA, Zhong KJY, Mazzulli T, Kain KC (2004) Evaluation of the RealArt Malaria LC Real-Time PCR Assay for Malaria Diagnosis. J. Clin Microbiol 42: 636-638.

13. Shokoples SE, Ndao M, Kowalewska-Grochowska K, Yanow SK (2009) Multiplexed Real-Time PCR Assay for Discrimination of Plasmodium Species with Improved Sensitivity for Mixed Infections. J Clin Microbiol 47: 975-980.

14. Abe A, Inoue K, Tanaka T, Kato J, Kajiyama N, et al. (1999) Quantitation of Hepatitis B Virus Genomic DNA by Real-Time Detection PCR. J Clin Microbiol 37: 2899-2903.

15. Dienstag JL, Perrillo RP, Schiff ER, Bartholomew M, Vicary C, et al. (1995) A preliminary trial of lamivudine for chronic hepatitis B infection. N Engl J Med 333: 1657-1661.

16. Gibson UE, Heid CA, Williams PM (1996) A novel method for real time quantitative RT-PCR. Genome Res 6: 995-1001.

17. Heid CA, Stevens J, Livak KJ, Williams PM (1996) Real time quantitative PCR. Genome Res 6: 986-994. 